\title{
Epidemiology of Dermatomycoses in Poland over the Past Decades
}

\author{
Katarzyna Kalinowska \\ Wroclaw Medical University \\ Poland
}

\section{Introduction}

Dermatophytes are keratinophilic and keratinolytic fungi. They are characterized by high affinity to keratin-containing tissues, what make them responsible for superficial mycoses of skin (tinea faciei, tinea barbae, tinea corporis, tinea cruris, tinea manuum or tinea pedis), nails (onychomycosis, tinea unguium) and hair (tinea capitis) (Kalinowska et al., 2009a).

Infections caused by dermatophyte fungi are very serious problem, not only clinical, but also epidemiological and therapeutic. The incidence of skin, hair and nail diseases does not depend on sex, age or social status.

\section{Short characteristic of dermatophytes}

There are many species of dermatophytes causing mycoses, so it is very important to assay them properly through mycological examination. Correct identification of the pathogen responsible for disease allows choosing a right treatment for patient.

Natural reservoir of dermatophytes is soil and keratin contained in soil is used as main nutrient for these fungi. However, evolutionary progress adapted these microorganisms to a various environments, so they generated ability to metabolize keratin derived not only from soil (Dworacka-Kaszak, 2004).

For that reason dermatophytes, with regard to their habitat, may be divided into antropophilic, zoophilic and geofilic species. For antrophophilic dermatophytes natural reservoir and carrier is human, zoophilic dermatophytes grow on domestic and stock animals and geophilic dermatophytes are found in soils (Adamski \& Batura-Gabryel, 2007).

In laboratory practice dermatophyte fungi belonging to three genera (Trichophyton, Microsporum, Epidermophyton), are known. Trichophyton and Microsporum genera are the most numerous and diverse, there are over 40 species belonging to these two taxonomic groups. Epidermophyton genus has only one representative - Epidermophyton floccosum species.

The genera Trichophyton is numerous and diverse, for example, in the Lower Silesia region, in years 2003 - 2007, these fungi were isolated in 92\% of all cultures (Jankowska-Konsur et al., 2011). 
In Poland, there are only few Trichophyton species, which are common, including:

- Trichophyton rubrum - antropophilic dermatophyte, distributed worldwide, usually specific to human, but infections in animals also have been reported. It may be the cause of practically all infections of body surface areas (with exception of fungal infections of the scalp). Most commonly it causes onychomycosis and athlete's foot (tinea pedis). It may also cause infections of glabrous skin (tinea corporis, tinea faciei), groin (tinea cruris), hands (tinea manuum) or nails (tinea ungiuim). This fungus causes persistent, chronic infections.

- Trichophyton mentagrophytes - zoophilic dermatophyte, cosmopolitan fungus, distributed worldwide. It causes infections in animals (cats, dogs, rabbits, guinea pigs, rodents, hedgehogs) as well as in human. Most commonly it causes infections of glabrous skin (tinea corporis, tinea faciei) and scalp infections (tinea capitis). Lesions often proceed with a large inflammatory reactions.

- Trichophyton tonsurans - antropophilic species, usually specific to human, practically cosmopolitan. Most commonly it causes infections of the scalp (tinea capitis) and it may also cause infections of glabrous skin (tinea corporis), especially in the "shower area" on neck, shoulder, back, buttocks, and feet, when inoculum is washed off from head on the other parts of the body, while taking shower. Infections usually proceed with mild inflammatory reaction, but cases with severe inflammatory responses also have been reported. This fungus often causes family and school outbreaks. It is also responsible for infections among wrestlers and judo competitors (tinea corporis gladiatorum). This dermatophyte is resistant to the adverse impact of external conditions and it is transferred by asymptomatic carriers.

- Trichophyton interdigitale - antropophilic species, distributed worldwide. It causes infections of feet (aspecially in the interdigital spaces) and hands (tinea manuum), sometimes it can also infect nails (tinea unguium).

- Trichophyton verrucosum - zoophilic species, the mostly isolated from cattle, it infects people, who work with these animals (farmers). Cosmopolitan fungus, it causes diseases of exposed parts of the body (tinea corporis) and face (tinea faciei), beard (tinea barbae) or head (tinea capitis).

- Trichophyton violaceum - antropophilic species, mostly it causes infections of the scalp (tinea capitis) and glabrous skin (tinea corporis), aspecially in the "shower area". It can also cause onychomycosis. It is specific to human, but it also can be pathogenic for animals. It is the cause of family and institutional outbreaks.

- Trichophyton schoenleinii - antropophilic species, it causes favus. Nowadays is practically unique.

Among Microsporum genera, only few species are common in lab-practice:

- Microsporum canis - zoophilic species, cosmopolitan, distributed worldwide. It is very contagious aspecially for young cats and dogs. In human it causes infections of the scalp (tinea capitis) and beard (tinea barbae) or infections of glabrous skin or face (tinea corporis, tinea faciei).

- Microsporum audouinii - antropophilic species, cosmopolitian, however, the incidence of fungal infections caused by this pathogen in Poland is very small. It causes infections of the scalp (tinea capitis), glabrous skin (tinea corporis), face (tinea faciei), affecting mostly school-age children (boys:girls=4:1), however cases of dermatomycoses in adults, 
caused by Microsporum audouinii also were described. Although it is human pathogen, it was isolated from fur of guinea pigs and rarely, from dog`s fur.

- Microsporum gypseum - geophilic species, ubiquitous, isolated from soils worldwide. Most exposed to infections are people, who cultivate the soil (farmers, gardeners), percentage of males prevails over females. Sometimes infection could be transmitted from animals. In human it causes infections of the scalp (tinea capitis) and glabrous skin (tinea corporis).

- Microsporum nanuum - zoophilic species, isolated also from soil. It causes infections among breeding cattle, mostly in pigs. In human it causes infections of the glabrous skin (tinea corporis) and the scalp (tinea capitis) proceeding with or without severe inflammation.

- Microsporum persicolor - zoophilic species, cosmopolitan. In human it causes infections of the scalp (tinea capitis), glabrous skin (tinea corporis) and feet (tinea pedis). Infections proceed with significant inflammatory reaction.

The genera Epidermophyton has only one representative, quite often isolated form lesions:

- Epidemophyton floccosum - antropophilic species, cosmopolitan. In human it causes mostly infections of the groin (tinea cruris), rarely of glabrous skin (tinea corporis), feet (tinea pedis) and very rarely of toenais (onychomycosis).

\subsection{Methods of pathogen transmission - a short description}

Dermatophytes are keratinophilic fungi, which parasitize on corneous structures, such as stratum corneum, hair or nails (Kobierzycka et al., 2005). Dermatophyte species are equipped with numerous enzymes, enabling them to survive on the skin and its appendages, because they have a proteolytic, keratinolytic and lipolytic activity. Furthermore the skin environment is conducive to dermatophytes because the corneal layer lacks blood vessels making it difficult to contact with immunologically competent cells and activate the defense mechanisms. On the surface of the epidermis are proteins, carbohydrates and micronutrients (including iron ions), which may provide substrates for the metabolism of fungi and help them to survive. Of great importance may also be some specific anatomic regions of the skin, greatly facilitating the colonization by fungi. Scalp hair can therefore arrest arthrospores spreaded by air. Similarly, spores are arrested in the hyponychium under or in the interdigital spaces, or in the folds of the skin where additionally oclusion helps them to develop (Dworacka-Kaszak, 2004). The spores are particularly resistant to environmental conditions, such as variable temperature and drying (Hryncewicz-Gwozdz et al., 2005; Kobierzycka et al., 2005). It is known that they can survive outside the host organism and colonize the skin and its appendages under favorable conditions, for example, in warm and humid environment, with increased amounts of $\mathrm{CO}_{2}$, which prevails in the poorly sheered shoes, it can lead to growth of the fungi and invasion of the skin structures.

To narrowly understand epidemiology of dermatomycoses, methods of pathogen transmission, are described below.

The sources of dermatophyte fungi infection are: human, animals and soil.

Infection with antropophilic dermatophytes may happen through direct contact with infected person, moreover spores of dermatophyte fungi can survive on skin and its 
appendixes without causing the disease (asymptomatic carrier) (Adamski \& BaturaGabryel, 2007).

Infection may occur also through some objects on which infectious material can be found (stratum corneum or hair with spores of fungi). The source of trunk, groin or extremities infections may be clothes, underwear or towels and sponges. Scalp diseases may happen through using the same brushes or combs. Shoes, socks, accessories for feet care or cosmetic pedicure are often the source of infections of feet and toenails.

Nails diseases are often connected with cosmetic manicure, infection may be a result of unsuitable disinfection of nails care accessories in cosmetic salons.

Also some public places could be potential source of antropophilic dermatomycoses - for example swimming-pools, toilets, showers, hotels, schools and similar (Bolinski et al., 2003, Szepietowski \& Baran, 2005).

Recently some cases of tinea corporis gladiatorum were described in literature. This type of dermatomycosis is common among wrestlers and judo competitors. The source of infection are athletes and wrestling mats (Hryncewicz-Gwozdz et al., 2011).

Similarly with zoophilic species - transmission of pathogen may happen through direct contact with an infected animal or animal being carrier of fungus. Zoophilic dermatophytes can be also transmited from human to human. The source of infection in children and adults are mostly domestic animals - cats, dogs, hamsters, guinea pigs, rabbits or even some birds. Farmers also often suffer from dermatomycoses transmitted from breeding cattle (pigs, cows, sheep, horses, goats) (Adamski Z \& Batura-Gabryel H., 2007).

Infection with geophilic dermatophytes usually happens as a result of contact with soil and it is common among people, who cultivate the soil (gardeners, farmers). The disease more often affect males than females. Working without protective gloves and unsuitable hygiene is conductive for transmission of pathogen. In literature were also described cases of transmission of geophilic dermatophytes through some animals (for example monkeys, mouses, leopards, rats, tigers) and insects (flies). Infection through direct contact with ill peoples occurs rather rarely (Kalinowska et al., 2009b)

\subsection{Clinical picture of dermatomycosis}

Fungi are present both in the natural environment and in the immediate surroundings of man. The host organism reaction to the infection with these pathogens is different and it depends greatly on what kind of dermatophyte causes it.

The main factor favourable to the development of fungal infection is a disorder of right microclimate of the skin, which is often caused by occlusion (poorly sheered clothes, shoes made of synthetic fabric) and microinjuries. Some diseases like diabetes and circulation disorders are of great importance in the development of mycoses (Macura \& Pawlik, 1998).

Clinical pictures of superficial mycoses are diverse, types of fungi infections are:

- Tinea capitis - infection of the scalp. When it is caused by antropophilic and zoophilic species ringworm of the scalp reveals the presence of foci of alopecia and scaling. The changes develop on erythematous base, but the severity of the inflammation is very 
diverse and in some individuals may it be a slight erythema. In extreme cases, the changes are soft with the presence of pustules and inflammatory tumors with pus or yellow crusts. This condition is called deep mycosis (kerion) and is the result of an inflammatory response to the presence of the fungus. Apart from very severe forms of deep fungal infection of the scalp, hair loss is usually transient. Even in the worst cases, regrowth occurs at a surprisingly high proportion. Exception is infection with antropophilic Trichophyton schoenleinii, which leads to scarring and permanent alopecia foci formation. Lesions very often are accompanied with itching.

- Tinea corporis - infection of the trunk and also extremities. Caused by antropophilic, zoophilic and geophilic species. Fungi, after infection of the skin form colonies and grow centrifugally. Lesions caused by antropophilic species form round or oval patches, which are spreading peripherally, and resolving and disappearing in the middle. In the part of the peripheral states moderate inflammation, redness and slight swelling, and even the production of pustules is seen. Lesions caused by zoophilic species characterize with significant inflammation, are well separated from the healthy skin, with exfoliation on the whole surface. Lesions are very often accompanied with itching.

- $\quad$ Tinea barbae - infection of the bearded area of men. Mostly it is caused by zoophilic species. Generally, the infection occurs as a follicular inflammation, or as a cutaneous granulomatous lesion, i.e. a chronic inflammatory reaction. It is one of the causes of folliculitis. Lesions are accompanied with itching. This infection is most common in farmers.

- $\quad$ Tinea faciei - infection of the glabrous skin of the face. It is caused by antropophilic and zoophilic species. Itchy lesions appearing on the face may be erythematous with exfoliation in the peripheral part or they may proceed with significant inflammation with the exfoliation on the entire surface.

- Tinea pedis - infection of feet and the interdigital spaces. Mostly it is caused by antropohilic species. In the interdigital variety, lesion appear in the folds between $3^{\text {rd }}$ and $4^{\text {th }}$ toes. The lateral surfaces of the toes and the bottom of folds are covered with layers and scales of keratinized epidermis. In the depth of the fold may appear cracks of the skin. Lesions may proceed on the dorsal and the basal surface of toes. There is a slight redness and exfoliation of the skin, and sometimes tiny vesicles and pustules may appear. The course is usually chronic, but it may be subject to intensify. On the plantar surface of feet occur eruptions similar to eczema. There are itchy follicles of various sizes. The course is chronic and recurrent, sometimes severe, however,complicated by purulent secondary infection and secondary prone to allergization.

- Tinea manuum - fungal infections of hands, it is caused by antropophilic species. Fungal infection of hands is almost always secondary to athlete's foot. Very rare primary form may develop in the case of occupational exposure to dermatophytes. Dermatophyte infections of hands can take several different clinical forms. The most commonly occurring is hiperkeratotic form, which is characterized by excessive keratosis of hands skin, with the presence of small and very adherent scales on erythematous base. Infectious process is typically subject to the fingertips. Also often coexists nail fungal infection. Less common is intertrigous form.

- $\quad$ Tinea cruris - dermatophyte infection of the groin, caused mostly by antropophilic species. In many patients the development of groin ringworm occurs through auto-infection from 
feet. It is revealed by the appearance of a typical erythematous lesions associated with exfoliation and itching, which spread on the upper surface of the thighs and crotch.

- Tinea unguium, Onychomycosis - dermatophyte infection of the nail plates. Mostly caused by antropophilic and very rarely by geophilic species. Changes within nail plates begin on free edge of nail and can cause excessive callus and fragility, appearance of grooves and fractures on surface of nail, the most often nail plates are turning yellow. Infected, untreated nails undergo gradually diminishing. Toenails are more often infected than fingernails. Fungal infection of toenails is often a result of athlete`s foot.

\subsection{Treatment of dermatomycosis}

There are many antifungal drugs, allowing for treatment dermatomycoses effectively.

These drugs can be divided to several groups :

- Antifungal antiseptics:

1. Iodine compounds

2. Phenol derrivates

3. Sulphur and its derrivates

4. Alcohol

5. Inorganic acids

6. Organic acids and their derrivates

7. Derrivates of unsaturated fatty acids

8. Aniline dyes

9. Heavy metals compounds

10. Quaternary ammonium hydroxides

11. Quinoline derrivates

12. Benzimidazole derrivates

- Antifungal antibiotics:

1. Polyene antibiotics (Natamycin)

2. Non-polyene antibiotcs (Gryzeofulvin)

- Antifungal chemioterapeutics :

1. Fluorpirimidine derrivates - flucytosine

2. Imidazole derrivates:

a. Azole drugs of the $1^{\text {st }}$ generation - Chlormidazole, Clotrimazole, Miconazole, Econazole, Izoconazole, Tioconazole, Bifonazole

b. Azole drugs of the $2^{\text {nd }}$ generation - Ketoconazole

c. Azole drugs of the $3^{\text {rd }}$ generation - Itraconazole, Fluconazole, Voriconazole, Posaconazole

3. Allyloamin derrivates - Naftifine, Terbinafine

4. Morpholine derrivates - Amorpholine

5. Pyridone derrivates - Cyclopirox

The mechanism of action of antifungal drugs is based on disruption of a fungal cell membrane or inhibition or disruption of DNA or RNA synthesis or inhibition of egrosterole synthesis in fungal cells.

Antifungal therapy should be selected to the type of dermatomycosis, some of them can be treated topically, others require systemic treatment. Sometimes, when fungal infection is difficult to treat, both of these therapies should be involved. 
Topical antifungal therapy is often the only procedure in the superficial mycoses of skin, it is decisive for the effectiveness of therapy. In cases of extensive and chronic superficial fungal infections of the scalp and nails, topical treatment is usually an essential element of combined therapy, shortening its duration and improves the treatment results.

The main indications for oral antifungal agents include the following infections :

- Fungal infections of nails and scalp

- Fungal infections involving large areas of skin

- Fungal infections in patients with immune disorders

- In a situation where there is a poor penetration of topical drug to the foci of fungal infection

- Persistent focus of fungal infection

To effectively treat fungal infections following conditions should be also applied:

- $\quad$ The correct mycological diagnosis before starting treatment.

- Removal of the factors predisposing to the development of fungal infection.

- Appropriate selection of drug.

- Knowledge of the principles of conducting antifungal treatment.

- Good cooperation with the patient.

- Control after treatment (clinical and mycological).

After complete cure of fungal infection, the physician should inform the patient about the the principles of prevention. This is especially important for onychomycosis, because these infections are often recurrent and chronic. For this purpose, patient should frequently disinfect shoes, wear cotton socks and avoid places with high humidity such as saunas, steam baths or swimming pools (Adamski \& Batura-Gabryel, 2007).

\section{Epidemiology of dermatomycoses in Poland over the past decades}

Within the past decades changes in percentage of fungal infections and spectrum of dermatophytes were observed - in given geographical regions appear new species, replacing the existing ones. Migration of population, industrialization, economic and cultural development, ageing of society, increased percentage of diseases like diabetes, circulation disorders, antibiotic therapy or taking of immunosuppressive medicines - these are the factors that are conductive to this phenomenon. There is a close relation between mycological biota isolated from skin and its appendages and changing spectrum of dematophyte fungi in environment (Wronski \& Nowicki, 2005).

\subsection{Geographical distribution of dermatophytes in Poland}

Studies on epidemiology of dermatomycoses in different parts of the world show how large changes can occur in the fungal biota in just a few decades. This phenomenon concerns also Poland and it is affected by changing environmental factors, including the formation of ever larger urban agglomerations, permanently changing profiles of the economy, and also clearly present in the last 15 - 20 years the changes in climatic conditions (Kobierzycka et al., 2005; Macura \& Pawlik, 1998; Szepietowski \& Baran, 2005). Of great importance is also easy to move to distant climatic - geographical regions - both tourist travel and mass migration 
for economic reasons. Thereby, various species of fungi appear far beyond the borders of the endemic areas.

The accumulated epidemiological data indicate how much the fungal biota of the given area, including Poland, changes over time. In the first half of the twentieth century in Central and Western Europe dominated zoophilic dermatophyte Trichophyton mentagrophytes, and today the predominant species is Trichophyton rubrum, antropophilic dermatophyte originating from Asia (Bajcar \& Ratka, 2002; Glinski et al., 2002, Szepietowski et al., 2001). Currently it is the most common etiological agent of fungal infections of toenails in Poland.

The increasing dominance of infections caused by Trichophyton rubrum appears to be a negative phenomenon, because these types of diseases are particularly chronic and often recurrent. As fungal infections of the skin and its appendages in different regions of the world are caused by different species of fungi, mycological biota present in the skin lesions is associated with changes in the natural environment and man's artificial environment. It is known that Trichophyton rubrum came to Poland during the mass migration after World War II (Macura\&Pawlik, 1998). This species was rare then, but over the years it has achieved a dominant position, while causing a permanent reduction in the participation of other dermatophyte infections of the skin and its appendages. Similarly, the major change relates to the presence on Polish territory The fungus Trichophyton schoenleinii. Today infections caused by this species are not found in Poland, but they occurred very often throughout the country in the first half of the twentieth century. Between 50`s and 60`s it caused only 5.7\% of fungal infections, and in the late 90 `s its isolation has already belonged to the casuistic rarity (Macura \& Pawlik, 1998; Szepietowski \& Baran, 2005). Increasing number of infections caused by other antropophilic dermatophyte was observed instead. Although Epidermophyton floccosum was only $0.7 \%$ of all isolated dermatophytes in the 70 's, then after 20 years the percentage of fungal infections increased 3 -fold, up to $2.23 \%$. Moreover, in place of Microsporum gypseum, which was only sporadically isolated in the 70`s of the twentieth century, occured an unprecedented then species Microsporum canis, taking the $3^{\text {rd }}$ position among the dermatophytes (2.64\%) (Macura\&Pawlik, 1998).

Mass migrations are particularly important and confirmed by epidemiological importance. It contributes to a large extent with spreading of fungal pathogens, especially antropophilic dermatophytes. The example is the African species (Trichophyton soudanense), and in the recent decades continuously isolated in Europe from immigrants coming from endemic areas. Similarly, in the U.S. athlete's foot cases caused by Trichophyton violaceum in immigrant from Asia, where this fungus is found endemic, were reported (Kobierzycka et al., 2005).

Interestingly, some species of dermatophytes found throughout the world, such as Microsporum audouinii and Trichophyton schoenleinii, are now very rare in the U.S. and Western Europe, although they are common in the other areas, particularly in Africa (Kobierzycka et al, 2005). Epidemiological data indicate that the changes that constantly occur in the distribution of pathogenic fungal biota are dependent on many factors. In addition to the progressive migration and climate change, social and economic conditions that affect skin exposure to fungal pathogens, and therapeutic methods are also important Szepietowski \& Baran, 2005). These factors significantly affect the changes in the proportion of different species of fungi at the time in a given area. Extremely rare occurrence of tinea 
capitis caused by Trichophyton schoenleinii in Poland now is mainly associated with progressive, improved sanitation in the second half of the twentieth century (Szepietowski \& Baran, 2005).

Given the fact that people are constantly exposed to the possibility of contact with dermatophytes, since infectious material is commonly present in the environment, in the case of infection with widespread antropophilic species it is difficult to identify the source and route of infection. Conversely, if the fungal infection is caused by zoophilic dermatophyte with a relatively narrow specificity of the species (Microsporum canis, Trichophyton verrucosum), and the number of actual cases is not large, the epidemiological investigation may allow to trace the spread of infection and determine its source (Kobierzycka et al., 2005).

Many years of studies of mycological biota indicate that one of its characteristics are constant changes in time, related to the presence of particular species of fungi in the natural environment and their involvement in causing infections of the skin and its appendages in human. Changing mycological biota varies in different geographical regions. Moreover, it was found that the clinical forms of fungal infections in different parts of the world are caused by different species of fungi (Chong \& Sinclair, 2000; Cribier \& Paul, 2001; Gupta, 2001). Tracing this variability is essential for epidemiological research, as it allows to prove the existence of variation ranges of the different species of dermatophytes. It also has no less important from the standpoint of public health, makes it possible to forecast the development of fungal infections in the population. Although Poland is a relatively small territory, epidemiological studies conducted in different parts of the country consistently show the changes in the fungal biota during the last 50 years.

Baran and Szepietowski analyzed results of mycological examinations from years 1988 1992, conducted across the country, updating epidemiological map of Poland (Baran \& Szepietowski, 1994). These researchers have demonstrated a definite advantage in the incidence of anthropophilic dermatophytes (64.3\% of all dermatophytes) over zoophilic dermatophytes (35\%). In addition, they found that infections with geophilic dermatophytes occured occasionally ( $0.7 \%$ of all isolated pathogens) (Figure 1$)$.

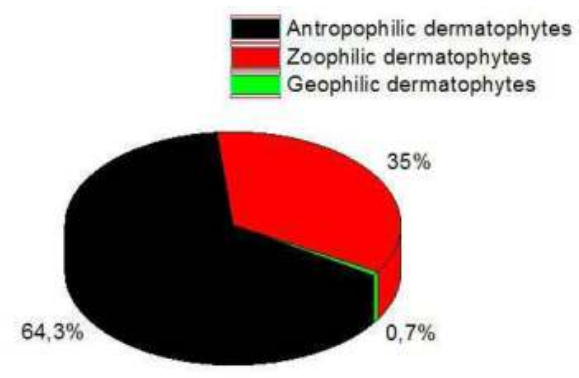

Fig. 1. Dermatophytes in Poland in years 1988-1992.

Anthropophilic dermatophytes dominance was observed in almost all regions of the country, but particularly clearly in the centraleastern region $(75.9 \%)$, midwestern region $(75.5 \%)$, southwestern region $(72.1 \%)$ and southeastern region $(70.4 \%)$. Only in the northern 
region of the country, this advantage was small, anthropophilic fungi accounted for only $54.6 \%$ of the total number of dermatophytes (Szepietowski \& Baran, 2005; Baran \& Szepietowski, 1994).

Quite different results were obtained in the province of Bialystok. Only in this region anthropophilic dermatophytes formed a minority, accounting for just $45.1 \%$ of all dermatophytes isolated in the area. It also appeared that the zoophilic fungi were the most common dermatophytes (54.9\%) in Bialystok province (northeastern Poland) (Szepietowski \& Baran, 2005; Baran \& Szepietowski, 1994). Authors found a clear upward trend in a southerly direction for the anthropophilic dermatophytes, closely associated with the occurrence of an inverse trend for zoophilic fungi (Szepietowski \& Baran, 2005). It turned out that zoophilic dermatophytes are the most commonly reported in the northern region $(45.4 \%)$ and least often in the middleeastern region (24.1\%). Baran and Szepietowski thus agreed that the distribution of zoophilic dermatophytes is the reverse of the map of anthropophilic dermatophytes distribution (Szepietowski \& Baran, 2005; Baran \& Szepietowski, 1994).

Among the anthropophilic fungi Trichophyton rubrum was isolated most frequently, it accounted for $45.5 \%$ off all dermatophytes and for anthropophilic dermatophytes $-70.8 \%$. This species occurred most frequently in the southwestern region $(59.1 \%$ of all dermatophytes), midwestern region (55.8\%) and southeastern region (53.4\%). Least often it was isolated in the northern region (7.7\% of all dermatophytes ascertained in this area). The second in the order, Trichophyton interdigitale usually occurred in the northern region $(34.0 \%$ of all dermatophytes), slightly less often $(24.5 \%)$ in the central-eastern parts of the country, but only occasionally - in the West $(0.6 \%)$. Epidermophyton floccosum was found the most frequently in the northeastern region (19.5\%) and the midwestern region $(15.6 \%)$, with a clear decrease in the incidence in the southern direction. Other species of anthropophilic dermatophytes were very rare, they were isolated only sporadically. In the group of zoophilic fungi Trichophyton mentagrophytes was mostly isolated. It accounted for $22.4 \%$ of all dermatophytes and among zoophilic dermatophytes it accounted for $64.4 \%$, and most occurred in the northeastern region (31.5\% of all dermatophytes), and the least in the region of central-western and south-western regions. Isolated somewhat less Microsporum canis constituted $9.7 \%$ of all dermatophytes and $27.6 \%$ of zoophilic dermatophytes. This fungus was typically found mostly in the northern region ( $21.5 \%$ of dermatophytes in this area), in the central region $(12.1 \%)$ and least often in the centraleastern region and northeastern regions (3.8\% and 0.5\%, respectively) (Baran \& Szepietowski, 1994).

Among the geophilic fungi, Microsporum gypseum was isolated most often. It represented only $0.6 \%$ of all dermatophytes and among geophilic dermatophytes - $82.8 \%$, and most frequntly occurred in the central region (Szepietowski \& Baran, 2005; Baran \& Szepietowski, 1994).

The authors analyzed the results of mycological examinations from the years 1988-1992 conducted across the country. The most often isolated fungus was antropophilic Trichophyton rubrum. Only in the northeastern region, in the province of Bialystok Trichophyton mentagrophytes was the most frequently observed species $(40.7 \%$ of all dermatophytes in the province). In the northern part of the Poland dominated Trichophyton interdigitale (34\% of all dermatophytes), although in the Gdansk region 
dominated infections caused by Microsporum canis (30.5\% of isolated dermatophytes) (Baran \& Szepietowski, 1994).

The results of this analysis showed how great epidemiological changes took place in relation to the occurrence of fungal pathogens, at a relatively small area of Poland in about 30 years. In the earlier years (1952-1967) a distinct advantage of zoophilic dermatopytes, representing $69.6 \%$ of the total dermatophytes over antropophilic $(30.3 \%)$ and geophilic dermatophytes $(0.1 \%)$ was observed (Figure 2). At that time, the dominance of zoophilic fungi did not concern only the region of Bialystok, where antropophilic dermatophytes accounted for $58.2 \%$ (Wronski \& Nowicki, 2000).

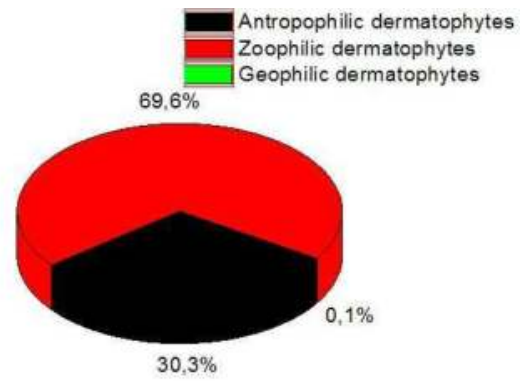

Fig. 2. Dermatophytes in Poland in years 1952-1967.

In the following years (1974-1979) more pronounced changes were observed in Poland, and the incidence of infections due to zoophilic and antropophilic dermatophytes became similar and amounted to $50.9 \%$ and $48.1 \%$, respectively (Lange et al., 2002). Geophilic dermatophytes constituted then only $1 \%$ (Hryncewicz-Gwozdz et al, 2005).

In the region of Olsztyn (northeastern Poland) incidence of zoophilic dermatophytes decreased from $51.7 \%$ in 1978-1981 to $48.8 \%$ in 1982-1986 (Nowicki \& Bykowska, 2006).

Increased frequency of isolation of anthropophilic fungi in relation to the zoophilic species, is confirmed by other studies - Ratka (1977-1988) and Baran et al in Lower Silesia (southwestern Poland) region (1977-1991) (Baran et al, 1993; Ratka, 1990). Over the years steadily increased the frequency of isolation of anthropophilic fungi among the dermatophytes. Previous studies showed that more than 40 years ago, most often isolated fungus in Poland was zoophilic Trichophyton mentagrophytes and Baran and Szepietowski showed that nowadays the most common species in Poland is Trichophyton rubrum (Baran \& Szepietowski, 1994; Wronski \& Nowicki, 2005) .

In the years 1987-1996 Kaszuba et al, studied fungal infections of the skin and its appendages in the Lodz region (Central Poland), they found that in the $51.7 \%$ of cases dermatophytes were the etiologic agent, including genera: Trichophyton (75.39\%), Microsporum (15.35\%) and Epidermophyton $(9.35 \%)$. Compared with studies from the years 1982-1986 the authors pointed out an increase in isolation of dermatophyte fungi in the Lodz region. The main etiological agent was Trichophyton rubrum $(34.15 \%)$, the second most common pathogen was Trichophyton mentagrophytes (33.19\%), and further were Microsporum canis and Epidermophyton floccosum. An interesting observation of the authors was significant change in the isolation frequency of Trichophyton mentagrophytes and Trichophyton rubrum species. It 
has been found a decrease of the incidence of Trichophyton mentagrophytes from over $50 \%$ to $33 \%$, while the number of isolation of Trichophyton rubrum has increased from $25 \%$ to $34 \%$ which places this species in the first place among diagnosed dermatophytes (Kaszuba et al., 1997).

Between 1995-1999 survey of fungal infections in the Wroclaw (Lower Silesia) region conducted Sikora et al (Sikora et al., 2000). A large variety of mycological biota was found. Among the dermatophytes, most often because $62.7 \%$ of infections concerned Trichophyton mentagrophytes, Trichophyton rubrum was isolated less frequently $(27.8 \%)$, Epidermophyton floccosum (6.2\%) and least often Microsporum canis (3\%). An important observation was a significant decrease in the number of infections caused by Trichophyton rubrum $(32.9 \%)$ and Epidermophyton floccosum (25.6\%). Moreover, the frequency of isolation of Trichophyton mentagrophytes grew by $61.5 \%$. In the case of Microsporum canis infections with this species increased to 1997, with subsequent later decrease of the number of infections (Sikora et al., 2000).

Between years 1996-2000 in region of Bydgoszcz (Central Poland) antropophilic Trichophyton rubrum was isolated in $41.6 \%$ of cases, followed by antropophilic Trichophyton interdigitale (26.9\%). Zoophilic Microsporum canis was isolated in 8.2\% of cases (Mrotek et al., 2001).

In the years 1996-2001 further studies concerned analysis of mycological biota and assessment of the incidence of fungal infections in patients from the urban environment of Bialystok. Anthropophilic dermatophytes were found in $40.1 \%$ of all isolates and among them most often were: Trichophyton rubrum, Trichophyton interdigitale, and Epidermophyton floccosum. Zoophilic dermatophytes represented $34.4 \%$ of fungi and most often occurred Trichophyton mentagrophytes. The results of studies conducted in region of Bialystok indicated the anthropophilic dermatophytes as the main etiological agents of fungal infections of the skin and its appendages (Bolinski et al., 2003).

Multiannual mycological research (1984-2001) were conducted in the Subcarpathian region (southeastern Poland) by Bajcar and Ratka. They compared in terms of epidemiology two periods: the years 1984-1993 and 1994-2001. Among isolated dermatophytes prevailed Trichophyton rubrum (68.9\% of all infections), and Trichophyton interdigitale was found in $11.3 \%$ of cases, Epidermophyton floccosum in $9.1 \%$ of cases, and Trichophyton tonsurans in $6.2 \%$ of cases. Zoophilic fungi were isolated rarely, in $4.1 \%$ of cases Trichophyton mentagrophytes was isolated. Comparing the results of research conducted in the years 1994-2001 with data obtained in the previous decade, Bajcar and Ratka observed in the Subcarpathian region continuing dominance of antropophilic fungi infections. Among the antropophilic dermatophytes was observed a decrease in the number of infections caused by Trichophyton rubrum (9.5\%) and an increased participation of Trichophyton interdigitale $(9.4 \%)$. An important observation of the authors was the emergence in the region of Subcarpathian an unprecedented Trichophyton violaceum species ( $0.4 \%$ of isolates) - species frequent in Eastern Europe. Comparing the two periods also a slight increase of fungal infections with zoophilic fungi was observed: Trichophyton mentagrophytes (from $4.1 \%$ to $5.5 \%$ ) and Trichophyton verrucosum (from $0.2 \%$ to $1.1 \%$ ) (Bajcar \& Ratka, 2002).

In the region of Gdansk Szarmach and Nowicki in years 1994-1998 found large share of dermatophytes as etiological agents of onychomycosis. They accounted for $44.8 \%$ of all fungal pathogens and most often isolated species were: Trichophyton rubrum and Trichophyton interdigitale (Szarmach \& Nowicki, 2001). 
Further studies conducted in Gdansk (midsouthern region of Poland) in years 2003-2005 showed an increase in the number of infections and variability of pathogenic fungi species. Among dermatophytes Trichophyton rubrum and Trichophyton mentagrophytes were recognized the most often $(43.9 \%$ and $35.6 \%$, respectively). These fungi were isolated mainly from toenails. Microsporum canis was isolated from $8.4 \%$ of patients, mostly from children it caused infections of the scalp (65.7\%) and glabrous skin (34.3\%) (Nowicki \& Bykowska, 2006). Moreover, this dermatophyte is the most common fungal pathogen among children in Gdansk region since 1984 (Wilkowska \& Nowicki, 1991).

Kalinowska et al studied dermatomycoses in Lower Silesia in years $2004-2008$. The author found, that pathogen isolated most fequently (59.27\%) was antropophilic Trichophyton rubrum, sencond most frequently isolated fungus was Trichophyton mentagrophytes $(22.09 \%)$. Interestingly, the incidence of dermatomycoses caused by Trichophyton tonsurans increased, and this dermatophyte was placed on the third position (10.45\%), followed by Microsporum canis $(4.74 \%)$ (Kalinowska et al., 2010).

Previous mycological research carried out in different regions of Poland indicate the need for constant observation and epidemiological analyses, to monitor ongoing changes of the fungal biota and its contribution to infections in human.

International Studies (Achilles project) conducted in 1989-1999 showed that Poland takes $4^{\text {th }}$ place after Russia, Hungary and the Czech Republic in the incidence of fungal infections in European countries (Glinski et al, 2002).

Among the 40,000 surveyed Poles $42 \%$ of them were diagnosed with athlete's foot and $21 \%$ with onychomycosis. The results of these studies additonally support the view that the epidemiological data of fungal infections must be constantly updated to confirmed variations of fungal biota in the natural environment.

From the 50`s of the past centrury, mycoses caused by zoophilic species represented up to almost $70 \%$ of diagnosed mycoses, whereas infections caused by antropophilic dermatophytes represented $30 \%$ and infections caused by geophilic dermatophytes represented $0.1 \%$ of all dermatomycoses. This situation has changed entirely in next decades, so different data are shown in literature from 1980s and 1990s - the most common were antropophilic dermatophytes $(64.3 \%)$, less common zoophilic dermatophytes $(35.0 \%)$ and infections caused by geophilic dermatophytes represented $0.7 \%$. Among antropophilic dermatophytes, Trichophyton rubrum is in the lead over past fifty years, this species is commonly responsible for onychomycosis. Among zoophilic dermatophytes, most frequently Trichophyton mentagrophytes was isolated. Among geophilic dermatophytes Microsporum gypseum was isolated most frequently.

Nowadays, depending on geographical region of Poland, antropophilic species represent about $45-75 \%$ of all dermatophytes and zoophilic species represent about $30-55 \%$.

\subsection{Epidemiology of different types of dermatomycoses in Poland}

Fungal infections are now a major epidemiological and social problem worldwide. According to various data relating to different geographical regions, they concern from 10 to $40 \%$ ofthe world's population (Bolinski et al., 2003; Foster et al., 2004; Kaszuba et al., 1997; Szepietowski \& Baran, 2005). Research conducted among people living in moderate climate 
zones showed chronic fungal infections among 10-20\% of the population (Bolinski et al., 2003; Glinski et al., 2002). Fungi pathogenic for human usually cause infections of the skin and its appendages, although in recent years also increasing recognition of fungal infections of internal organs is seen.

Among the more than 200000 species of fungi about 200 are pathogenic to human (Szepietowski \& Baran, 2005). Their high morphological diversity allows them to survive in different ecosystems. Polymorphism of fungi is also a result of their diverse needs for growth substances in certain ecological niches, because they have a high potential to adapt to the changing resources of their environment (Dworacka-Kaszak, 2004). Among potential fungal skin pathogens are fungi not only highly adapted for parasite on the skin dermatophytes, but also yeasts and molds.

Observed in recent decades, the increasing incidence of fungal infections of the skin is mainly associated with the constant presence, and even an increase in risk factors for fungal infections. It was established a number of factors predisposing to the development of fungal infections, some of which relate to the host, and other to biological characteristics of the fungal pathogens. One of the main factors is prolongation of the average life span, age proved to be a physiological risk factor for fungal infection. Particularly predisposed group are not only people over 65 years, but also premature newborns and infants. It was found that the presence of multifocal skin infections increases with age and is 2-fold more frequent in men than in women (Kobierzycka et al., 2005).

One of the most important factors influencing the increasing number of fungal infections is the progress in medical science, it now allows the survival of patients with an impaired immune response in the course of chronic, severe illnesses such as cancer, metabolic and endocrine diseases, renal failure, HIV infection and other (Hryncewicz, Gwozdz et al., 2006; Miroszewska-Sobanska \& Adamski, 2000). This is related to the development of intensive medical care, dialysis, parenteral nutrition and artificial ventilation, conducting invasive diagnostics, catheterization of vascular and body cavities, and also with the use of modern cardiac transplantation techniques (Glisnki et al., 2002). Very important is also antibiotic therapy, treatment with cytostatics, immunosuppressants and corticosteroids (KrajewskaKulak et al., 2000).

Superficial mycoses of skin and its appendages are diagnosed in Poland very often. Among the clinical forms of mycoses of skin and its appendages special place because of the prevalence takes athlete's foot and onychomycosis. Athlete's foot occurs mostly in adults, rarely in children and often is acquired early in adolescence.

For example, studies of Kalinowska et al on lowersilesian population in years 2004-2008 indicated, that tinea pedis and onychomycosis were very often in adults, whereas in children and adolescents tinea capitis and tinea corporis were predominated (Kalinowska et al., 2010). It is believed that in developed countries athlete`s foot may affect up to $10 \%$ of the total population. In recent years, it was found that for most cases of athlete's foot are responsible three anthropophilic species of dermatophytes: Trichophyton rubrum, Trichophyton interdigitale and Epidermophyton floccosum (Kobierzycka et al., 2005).

Studies of Szepietowski et al indicate that the athlete's foot was $28 \%$ of all fungal infections of skin and nails in Poland and it is the second most common after onychomycosis. Other 
authors estimate the incidence of fungal infection rates similar of $25-30 \%$ in the general population, although this is difficult to determine it because in the special risk groups (athletes, miners), it can grow up to $60-70 \%$. In studies of Szepietowski et al most common type of tinea pedis was a athlete's foot $(45.5 \%)$, and the most common pathogens causing it were dermatophytes, which were isolated in $88.8 \%$ of all patients with fungal infections. Among the most commonly cultured dermatophytes were Trichophyton rubrum (51\%), followed by Trichophyton mentagrophytes (33.1\%) (Szepietowski et al., 2001).

The authors found that athlete's foot in $75.2 \%$ of patients occurred together with the other forms of fungal infection of the skin, the most common was onychomycosis found in $69.2 \%$ of patients. Described in the literature the simultaneous occurrence of fungal infection of the both feet with one hand forming the so-called two feet and one hand syndrome and was rarely observed, because only in $2.5 \%$ of patients (Szepietowski et al., 2001). It is believed that the probability of developing athlete's foot is lower in women than in men. The differences are likely to result from increased exposure to pathogenic fungi associated with wearing heavy occlusive footwear by men (Kobierzynska et al., 2005).

Onychomycosis is often concomitant with athlete`s foot, it is developed by the occurrence of the same favorable environmental conditions for fungi (Elewski, 2000a; HryncewiczGwozdz et al., 2005; Wronski \& Nowicki, 2005). Infections concerns mostly the elderly, after 65 years. Its occurence is much rarer in children, it is associated with rapid growth of the nails in young people which hinders the development of infection because the fungus is removed together with the growing plate (Hryncewicz-Gwozdz et al., 2006; Lange \& Bykowska, 2004). Epidemiological data from recent years show significant dominance of dermatophyte fungi as a etiological agents of onychomycosis. It is assumed that currently about $80 \%$ of fungal infections of nails are caused by Trichophyton rubrum (Wronski \& Nowicki, 2000).

Fungal infection of hands is most common as a secondary infection in patients with athlete`s foot. It can then concern the dominant hand and form the aforementioned two feet and one hand sydrome (Szepietowski et al., 2001). In most cases the etiological factors for mycosis of hands are anthropophilic species of dermatophytes that also cause athlete's foot also: Trichophyton rubrum, rarely Epidermophyton floccosum and Trichophyton interdigitale. Much less fequently hand's skin can be infected by antropohilic species Trichophyton violaceum and some zoophilic species such as Trichophyton mentagrophytes (Kobierzycka et al., 2005; Hryncewicz-Gwozdz et al., 2005) .

The development of fungal infection of the hands may facilitate various factors causing maceration of the skin, such as wearing rings, watches, anatomical deformities, and environmental factors associated with the professional activities (Kobierzycka et al., 2005).

Species of dermatophytes that cause athlete's foot can also cause fungal infection of the groin. The most common pathogen is Trichophyton rubrum, while Trichophyton interdigitale and Epidermophyton floccosum more rarely cause infections of this area. This infection is a common disease, occurring more often in men than in women, but it is rarely observed in children. Tinea cruris is a very widespread in the tropics, particularly among immigrants from countries with temperate climates, especially when factors that makes them predisposed to the formation of intertrigos and development of fungal infections are accumulated (Kobierzycka et al., 2005). 
Most dermatophytes can infect hair, the exceptions are, however, some species such as Epidermophyton floccosum, Trichophyton rubrum, Trichophyton interdigitale. Conversely, some dermatophytes (Microsporum audouinii, Trichophyton schoenleinii, Trichophyton violaceum) have a strong affinity for hair structures. It was found that all the dermatophytes, which cause fungal infections of the scalp can also infect glabrous skin (Kobierzycka et al., 2005). Pathogens that cause tinea capitis differs between countries and geographic regions. In recent years, it has been observed in most European countries, an increase in the frequency of infections caused by Microsporum canis, whereas in the U.S. urban environments - a larger share Trichophyton tonsurans was seen (Elewski, 2000b). Mycosis of the scalp concerns mainly children. Peak incidence falls on $4-6$ years of age, and the infection is spreading especially in boys. Higher incidence of fungal infections in children is associated with the difference of biological characteristics of the skin, including the different composition of sebum in children and adults (Szepietowski \& Baran, 2005).

In a study of Lange et al, of the pediatric population in the region of Gdansk (midsouthern Poland), fungal infections of skin were usually caused by dermatophytes, which accounted for $60 \%$ of all infections. The highest incidence of skin fungal infections was observed in children aged 4-7 years. In this age group, the lesions caused by Microsporum canis affected the scalp. In slightly older children, aged 8-12 years, the number of infections of the scalp decreased rapidly, and over 13 years of age lesions in this location rarely have been observed. Most common form of fungal infection, that was seen in the pediatric population studies, was fungal infection of the glabrous skin (30\%), mostly caused by Microsporum canis, rarely by Trichophyton mentagrophytes and by Trichophyton rubrum, occurring most often in children aged 8 - 15 years. It is interesting that in children above 12 years of age athlete's foot was also observed (11\%), in most cases caused by Trichophyton rubrum and Trichophyton mentagrophytes, and also fungal infections of the toenails (8\%) caused by Trichophyton rubrum were seen (Lange et al., 2002). Similar results were obtained in the studies of pediatric patients in the region of Poznan (Central-West Poland) (Zaba \& Danczak-Pazdrowska, 2001).

Many authors underline the rarity of these forms of mycoses in children before puberty, in contrast to the fungal infections of glabrous skin and scalp, considered to be typical for the childhood. Accepted view is that the athlete's foot and onychomycosis are very common skin and nails diseases in adults, and their incidence increases with age. However, epidemiological studies on the population of children of different ages and in different regions of the world indicate that the athlete's foot may relate to $2.2-8.2 \%$ of the pediatric population (Lange \& Bykowska, 2004) In addition, there are also cases of athlete's foot in pediatric patients like tinea incognito, proceeding without symptoms or mistakenly acknowledged as bacterial lesions or allergic changes and treated with antibiotics or topical cortycosteroids (O`Grady \& Sahn, 1999).

Studies of Lange and Bykowska on recognition of fungal infections in pediatric patients in years 1993-2002 showed an increase in the prevalence rates of onychomycosis in children (Lange \& Bykowska, 2004). In the literature, individual national studies of mycoses of the feet and toenails in children and adolescents refers to the area of Wroclaw (Lower Silesia, southwestern Poland), where there has been considerable percentage of fungal infection of the feet and toenails in children under 15 years of age $(16.3 \%$ and $21 \%$, respectively) (Szepietowski, 1997). 
Also, Zaba and Danczak-Pazdrowska examining children and adolescents to 18 years of age, living in the area of Greater Poland, found fungal infections of toenails in $34.5 \%$ patients and mycoses of hands and feet in $26.1 \%$ of cases (Zaba \& Danczak-Pazdrowska, 2001). It seems that a particular risk factor in children is a participation in sport activities. It turned out that in this group superficial mycosis of the feet occurs several times more often than in children not involved in sport, which is related to use of occlusive footwear, as well as frequent, repetitive injuries of fingers and toenails. Thus, the results of the Polish authors suggest that fungal infection of the feet and toenails in children and adolescents currently are not that uncommon. Moreover, as in adults, athlete's foot in children can coexist with other clinical forms of fungal infection, especially fungal infection of the toenails (Lange \& Bykowska, 2004).

The analysis of few described so far cases in the world of dermatomycosis in newborns showed that it could even occur on the second day of life and can be caused both by anthropophilic dermatophytes (Trichophyton rubrum) and as well as zoophilic dermatophytes (Microsporum canis). The source of infection in case of antropophilic dermatophytes was immediate family and in case of zoophilic dermatophytes - pets, especially cats. Descriptions analyzed by Szepietowski of dermatomycosis in newborns come mostly from India and Japan, which is probably related both to climatic conditions, as well as significantly to local practices for baby care (Szepietowski, 1997).

\section{Conclusion}

Fungal infections are a serious problem - not only clinical, but also therapeutic and social. Fungi are widespread in the environment of human life, are ubiquitous, so the disorders caused by them could be classified as a lifestyle diseases, affecting people independtly of age, sex, race or social status. Fortunately, our knowledge about these parasites of the skin and its appendages is growing, new therapies and new methods of treatment of fungal diseases are developed, which allows us to effective protection against these pathogens.

\section{References}

Adamski, Z. \& Batura - Gabryel, H. (2007). Medical mycology for physicians and students, $2^{\text {nd }}$ edition. Scientific Publishing of Poznan Medical University, Poznan, Poland, ISBN 978-83-60187-76-0

Bajcar, S \& Ratka P. (2002). Epidemiology of dermatophyte infections among inhabitans of Subcarpathian region in years 1984-2001. Mikologia Lekarska, Vol. 9, No. 2 (June), pp. 101-104, ISSN 1232-986X

Baran, E. \& Szepietowski J. (1994). Geographical distribution of dermatophytes isolated from skin lesions in Poland. Mikologia Lekarska, Vol. 1, No. 1 (March), pp. 11-18, ISSN 1232- 986X

Baran, E. et al. (1993). Fungal infections in Lower Silesia region in years 1974-1988. Przeglad Dermatologiczny, Vol. 80, pp. 49-58, ISSN 0033-2526

Bolinski, J. et al. (2003). Epidemiology of infections of skin and its appendages in material of Dermatology Clinic in Bialystok. Mikologia Lekarska, Vol. 10, No. 2 (June), pp. 119127, ISSN 1232-986X 
Chong, A. \& Sinclair, R. (2000). Diagnosing superficial mycoses. American Journal of Clinical Dermatology, Vol. 1, No. 2 (March-April), pp. 125-131, ISSN 1175-0561

Criber, B. \& Paul, C. (2001). Long-term efficacy of antifungals in toenail onychomycosis: a critival review. British Journal of Dermatology, Vol. 145, No. 3, pp. 446-452, ISSN 1365- 2133

Dworacka-Kaszak, B. (2004). Dermatophytes. Keratophilic fungi and their role in environment. Mikologia Lekarska, Vol. 11, No. 4 (December), pp. 317-322, ISSN 1232986X

Elewski, B. (2000a). Onychomycosis. Treatment, quality of life and economic issues. American Journal of Clinical Dermatology, Vol. 1, No. 1 (January-February), pp. 19-26, ISSN 1175-0561

Elewski, B. (2000b). Tinea capitis: a current perspective. Journal of the American Academy of Dermatology, Vol. 42, No. 1 (January), pp. 1-20, ISSN 1175-0561

Foster, K., Ghannoum, M. \& Elewski, B. (2004). Epidemiologic surveillance of cutaneous fungal infections in the United States from 1999-2001. Journal of the American Academy of Dermatology,Vol. 50, No. 5 (May), pp. 748-752, ISSN 1097-6787

Glinski, W. et al., (2002). Consensus concerning treatment of superficial fungal infections. Przeglad Dermatologiczny, Vol. 89, pp. 85-92, ISSN 0033-2526

Gupta, A. (2001). Cyclopirox: an overview. International Journal of Dermatology, Vol. 40, No. 5 (May), pp. 305-310, ISSN 1365-4632

Hryncewicz-Gwozdz, A., Plomer-Niezgoda, E \& Maj, J. (2005). Mycoses of feet, hands and nails - epidemiology, symptoms, treatment. Mikologia Lekarska, Vol. 12, No. 1 (March), pp. 57-62, ISSN 1232-986X

Hryncewicz-Gwozdz, A. et al. (2011). Tinea Capitis and Tinea Corporis with a Severe Inflammatory Response due to Trichophyton tonsurans. Acta Dermato-Venereologica, Epub ahead of print, ISSN 0001-5555

Hryncewicz-Gwozdz, A. et al. (2006). Mycosis of nails - current clinical and epidemiological aspects in Poland. Mikologia Lekarska, Vol. 13, No. 2 (June), pp. 137-142, ISSN 1232986X

Jankowska-Konsur, A. et al. (2011). A 5-year survey of dermatomycoses in southwest Poland, years 2003-2007. Mycoses, Vol. 54, No. 2 (March), pp. 162-167, ISSN 14390507

Kalinowska, K., Hryncewicz-Gwozdz A. \& Plomer-Niezgoda E., (2009a). Differential of Trichophyton species. Mikologia Lekarska, Vol. 16, No. 3 (September), pp. 171-177, ISSN 1232-986X

Kalinowska K, Hryncewicz-Gwozdz A. \& Plomer-Niezgoda E. (2009b). Dermatomycoses due to Microsporum audouinii and Microsporum gypseum. Mikologia Lekarska, Vol. 16, No. 3 (September), pp. 179-183, ISSN 1232-986X

Kalinowska, K. et al. (2010). Epidemiology of dermatophytoses in Lower Silesia in years 2004-2008. Mikologia Lekarska, Vol. 17, No. 3 (September), pp. 165-168, ISSN 1232986X

Kaszuba, A. et al. (1997). Dermatophytes in infections of skin and its appendages in people I n Lodz region. Mikologia Lekarska, Vol. 4, No. 4 (December), pp. 211-216, ISSN 1232986X

Kobierzycka, M. et al. (2005). Epidemiology and diagnostic of the most common mycoses of glabrous and hairy skin. Terapia, Vol. 13, No. 1, pp. 53-58, ISSN 1230-3917 
Krajewska-Kulak, E., et al. (2000). Nosocomial fungal infections-an increasing problem. Mikologia Lekarska, Vol. 7, No. 3, (September) pp. 159-163, ISSN 1232-986X

Lange, M. et al. (2002). Mycotic infections of skin and and mucous membranes in children in the district of Gdansk between 1999-2001. Mikologia Lekarska, Vol. 9, No. 2 (June), pp. 75-81, ISSN 1232-986X

Lange, M. \& Bykowska, B. (2004). Tinea pedis and toenail onychomycosis in children and adolescents - clinical types and pathogens. Mikologia Lekarska, Vol. 11, No. 1 (March), pp. 63-69, ISSN 1232-986X

Macura, A. \& Pawlik, B. (1998). Analysis of mycological flora causing superficial fungal infections in the last decade. Mikologia Lekarska, Vol. 5, No. 1, pp. 51-61, ISSN 1232986X

Miroszewska-Sobanska, T., Adamski, Z. (2000). Prophylaxis of fungal infections. Postepy Dermatologii i Alergologii, Vol. 18, No. 3, pp. 181-188, ISSN 1642-395X

Mrotek, M. et al. (2001). Pathogenic fungi in the material of Mycological Laboratory of the Dermatology Clinic in Bydgoszcz in the period January 1996-August 2000. Mikologia Lekarska, Vol. 8, No. 3 (September), pp. 153-157, ISSN 1232986X

Nowicki, R. \& Bykowska, B. (2006). Dermatomycoses among inhabitants of the Pomeranian province in the years 2003-2005. Mikologia Lekarska, Vol. 13, No. 2 (June), pp. 119122, ISSN 1232-986X

O Grady, T. \& Sahn E. (1999). Investigation of asymptomatic tinea pedis in children. Journal of the American Academy of Dermatology, Vol. 24, No. 4, pp. 660-661, ISSN 10976787

Ratka, P. (1990). Epidemiology of fungal infections in Poland in years 1977-1988. Postepy Dermatologii i Alerologii, Vol. 7, pp. 207-213, ISSN ISSN 1642-395X

Sikora, M. et al. (2000). Analysis of fungal skin and skin appendages infections in the region of Wroclaw in the years 1995-1999. Mikologia Lekarska, Vol. 7, No. 3 (September), pp. 145-151, ISSN 1232-986X

Szarmach, A. \& Nowicki, R. (2001). Mycosis of nails due to dermatophytes in the material of Dermatology Clinic of Gdansk Medical University in the years 1994 - February 1998 -mycological, morphological and clinical aspect. Mikologia Lekarska Vol. 8, No. 2 (June), pp. 55-62, ISSN 1232-986X

Szepietowski, J. \& Baran, E. (2005). Epidemiology of mycoses. In: Outline of mycology of nurses. E. Krajewska-Kulak (Ed.), 31-35, Czelej Publishing, Lublin, Poland, ISBN 83- 89309-54-8

Szepietowski, J., Baran, E. \& Wild, E. (2001). Mycosis of feet - clinical types and pathogens. Przeglad Dermatologiczny, Vol. 886, pp. 497-502, ISSN 0033-2526

Szepietowski, J. (1997). Mycosis of skin in newborns. Mikologia Lekarska, Vol. 4, No. 1 (March), pp. 41-45, ISSN 1232-986X

Wilkowska, A. \& Nowicki, R. (1991). Microsporiasis in patients treated in Dermatology Clinic of Gdansk Medical University. Przeglad Dermatologiczny, Vol. 78, pp. 38-42, ISSN 0033-2526

Wronski A. \& Nowicki, R. (2000). Etiology of superficial fungal infection in contemporary mycological diagnostic methods. Mikologia Lekarska, Vol. 12, No. 3 (September), pp. 197-202, ISSN 1232-986X 
Zaba, R. \& Danczak-Pazdrowska, A. (2001). Analysis of mycoses in children - patients of City Hospital in Poznan in the years 1996-2000. Mikologia Lekarska, Vol. 8, No. 2 (June), pp. 106-109, ISSN 1232-986X 


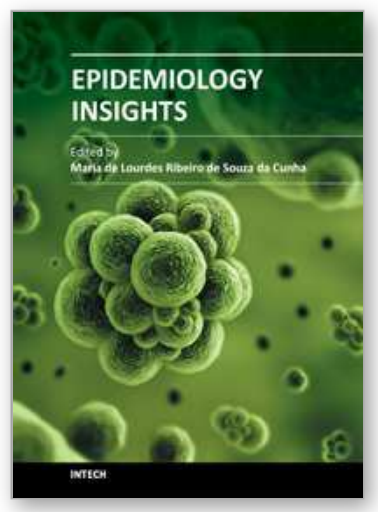

\author{
Epidemiology Insights \\ Edited by Dr. Maria De Lourdes Ribeiro De Souza Da Cunha
}

ISBN 978-953-51-0565-7

Hard cover, 396 pages

Publisher InTech

Published online 20, April, 2012

Published in print edition April, 2012

This book represents an overview on the diverse threads of epidemiological research, brings together the expertise and enthusiasm of an international panel of leading researchers to provide a state-of-the art overview of the field. Topics include the epidemiology of dermatomycoses and Candida spp. infections, the epidemiology molecular of methicillin-resistant Staphylococcus aureus (MRSA) isolated from humans and animals, the epidemiology of varied manifestations neuro-psychiatric, virology and epidemiology, epidemiology of wildlife tuberculosis, epidemiologic approaches to the study of microbial quality of milk and milk products, Cox proportional hazards model, epidemiology of lymphoid malignancy, epidemiology of primary immunodeficiency diseases and genetic epidemiology family-based. Written by experts from around the globe, this book is reading for clinicians, researchers and students, who intend to address these issues.

\title{
How to reference
}

In order to correctly reference this scholarly work, feel free to copy and paste the following:

Katarzyna Kalinowska (2012). Epidemiology of Dermatomycoses in Poland over the Past Decade, Epidemiology Insights, Dr. Maria De Lourdes Ribeiro De Souza Da Cunha (Ed.), ISBN: 978-953-51-0565-7, InTech, Available from: http://www.intechopen.com/books/epidemiology-insights/epidemiology-ofdermatomycoses-in-poland-over-the-past-decades

\section{INTECH}

open science | open minds

\author{
InTech Europe \\ University Campus STeP Ri \\ Slavka Krautzeka 83/A \\ 51000 Rijeka, Croatia \\ Phone: +385 (51) 770447 \\ Fax: +385 (51) 686166 \\ www.intechopen.com
}

\author{
InTech China \\ Unit 405, Office Block, Hotel Equatorial Shanghai \\ No.65, Yan An Road (West), Shanghai, 200040, China \\ 中国上海市延安西路65号上海国际贵都大饭店办公楼 405 单元 \\ Phone: +86-21-62489820 \\ Fax: +86-21-62489821
}


(C) 2012 The Author(s). Licensee IntechOpen. This is an open access article distributed under the terms of the Creative Commons Attribution 3.0 License, which permits unrestricted use, distribution, and reproduction in any medium, provided the original work is properly cited. 